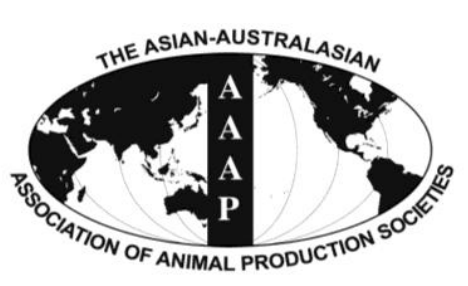

Open Access

Asian Australas. J. Anim. Sci.

Vol. 28, No. 3 : 391-397 March 2015

http://dx.doi.org/10.5713/ajas.14.0463

www.ajas.info

pISSN 1011-2367 elSSN 1976-5517

\title{
Effect of Dietary Marine Microalgae (Schizochytrium) Powder on Egg Production, Blood Lipid Profiles, Egg Quality, and Fatty Acid Composition of Egg Yolk in Layers
}

\author{
J. H. Park, S. D. Upadhaya, and I. H. Kim* \\ Department of Animal Resource and Science, Dankook University, Cheonan 330-714, Korea
}

\begin{abstract}
Two hundred and sixteen Institut de Sélection Animale (ISA) brown layers (40 wks of age) were studied for 6 wks to examine the effect of microalgae powder (MAP) on egg production, egg quality, blood lipid profile, and fatty acid concentration of egg yolk. Dietary treatments were as follows: i) CON (basal diet), ii) $0.5 \%$ MAP (CON+0.5\% Schizochytrium powder), and iii) $1.0 \%$ MAP $(\mathrm{CON}+1.0 \%$ Schizochytrium powder). From 44 to $46 \mathrm{wks}$, egg production was higher in $1.0 \%$ MAP treatment than in control treatment (linear, $\mathrm{p}=0.034$ ); however, there was no difference on the egg production from 40 to $43 \mathrm{wks}(\mathrm{p}>0.05)$. Serum triglyceride and total cholesterol were significantly reduced in the groups fed with MAP, compared to those in groups fed with control diets (Quadratic, $\mathrm{p}=$ 0.034 and $p=0.039$, respectively). Inclusion of $0.5 \%$ MAP in the diet of layers improved egg yolk color, compared with hens fed with basal diet at 46 wks (quadratic, $p=0.044$ ). Eggshell thickness was linearly increased in MAP-fed treatments at 46 th wk ( $<<0.05$ ). Concentration of yolk docosahexaenoic acid (DHA; C22:6n-3) was increased in treatment groups fed with MAP (linear, $\mathrm{p}<0.05$ ). The n6 fatty acids, n-6/n-3 fatty acid, and unsaturated fatty acid/saturated fatty acid were decreased in treatment groups fed with MAP (linear, $\mathrm{p}<0.05)$. These results suggest that MAP improved the egg production and egg quality, and may affect serum lipid metabolites in the layers. In addition, MAP increases yolk DHA levels, and deceases n-6/n-3 fatty acid ratio. (Key Words: Egg Production, Fatty Acid, Laying Hen, Microalgae, Schizochytrium)
\end{abstract}

\section{INTRODUCTION}

Among various marine resources, microalgae has recently received worldwide attention, as a potent source for biodiesel, cosmetics and organic fertilizers. Furthermore, microalgae has also been utilized as a source of protein and fiber for nutritional supplementation in humans, and its application has been extended to domestic livestock (Lum et al., 2013; Gatrell et al., 2014).

Microalgae has an excellent nutritive value. It is a rich source of essential amino acids, vitamins, minerals, carotenoids and fatty acids (Becker, 2004). In addition, microalgae has many potential health promoting effects, such as antioxidant activity, immune stimulating properties, decreasing blood pressure and cholesterol, and promoting

\footnotetext{
* Corresponding Author: I. H. Kim. Tel: +82-41-550-3652, Fax: +82-41-565-2949, E-mail: inhokim@ dankook.ac.kr Submitted Jun. 25, 2014; Revised Aug. 7, 2014; Accepted Sept. 13, 2014
}

growth of beneficial microorganisms in the intestine (Jimenez-Escrig et al., 2001; Hata et al., 2002; Hirahashi et al., 2002; Spolaore et al., 2006; Dvir et al., 2009). The dietary supplementation of microalgae rich in docosahexaenoic acid (DHA) increases DHA content in milk fat of dairy cattle, muscle tissue of pigs, and the egg yolk of layers (Becker, 2004; Sardi et al., 2006; Stamey et al., 2012). Moreover, microalgae in poultry diets can be effectively used as a natural pigment source, both in egg yolk, and in broiler skin (Herber and Van Elswyk, 1996; Sardi et al., 2006).

Microalgae is abundant, has a rapid growth rate and is thought to be an attractive feed additive, because of its digestible protein and long-chain omega-3 fatty acids, which could be substituted for fish oils or flaxseed and canola oils (Trentacoste et al., 2013). Although microalgae has high potential for use as an animal feed additive, researches on the effect of microalgae are insufficient in 
layers. Therefore, the aim of this study was to investigate the effect of marine microalgae, Schizochytrium with rich DHA on egg production, egg quality, blood profiles, and fatty acid composition of egg yolk in layers.

\section{MATERIALS AND METHODS}

\section{Experimental birds and design}

All animal-based procedures were in accordance with the Guidelines for the Care and Use of Experimental Animals of Dankook University.

A total of 216 Institut de Sélection Animale (ISA) brown commercial layers $(1,835 \mathrm{~g} \pm 42)$ were randomly assigned to 3 treatments, with 12 replications of 6 hens in each treatment, during 40 to $46 \mathrm{wks}$ of age. Six layers were housed per $114 \times 50 \times 40 \mathrm{~cm}$ wire cage, and were subjected to a photoperiod of $16 \mathrm{~h}$ light and $8 \mathrm{~h}$ dark/d. Layers were fed mash diets, formulated to supply their nutritional requirements (NRC, 1994) (Table 1). Feed and water were provided ad libitum. Dietary treatments were as follows: i) CON (basal diet); ii) $0.5 \%$ microalgae powder (MAP;

Table 1. Basal diet composition (as-fed basis)

\begin{tabular}{lc}
\hline Items & \\
\hline Ingredients (\%) & 56.28 \\
Corn & 15.53 \\
Soybean meal $(46 \% \mathrm{CP})$ & 10.00 \\
Wheat grain & 2.00 \\
Corn gluten meal (60\% CP) & 5.00 \\
Wheat bran & 1.70 \\
Tallow & 7.52 \\
Limestone & 1.37 \\
Dicalcium phosphate $(18 \%$ P) & 0.30 \\
Salt & 0.10 \\
DL-met (50\%) & 0.10 \\
Vitamin premix ${ }^{1}$ & 0.10 \\
Trace mineral premix ${ }^{2}$ & \\
Calculated energy content & 2,700 \\
ME ${ }^{3}$ (kcal/kg) & \\
Analyzed nutrient content $(\%)$ & 17.04 \\
CP & 3.98 \\
Ether extract & 0.78 \\
Lys & 0.63 \\
Met+cys & 3.45 \\
Ca & 0.61 \\
Total P & \\
\hline &
\end{tabular}

$\mathrm{CP}$, crude protein; $\mathrm{ME}$, metabolizable energy.

${ }^{1}$ Provided per kilogram of diet: 12,500 IU vitamin A; 2,500 IU vitamin $\mathrm{D}_{3} ; 13 \mathrm{IU}$ vitamin $\mathrm{E} ; 2 \mathrm{mg}$ vitamin $\mathrm{K}_{3} ; 1 \mathrm{mg}$ vitamin $\mathrm{B}_{1} ; 5 \mathrm{mg}$ vitamin $\mathrm{B}_{2} ; 1 \mathrm{mg}$ vitamin $\mathrm{B}_{6} ; 0.04 \mathrm{mg}$ vitamin $\mathrm{B}_{12} ; 0.9 \mathrm{mg}$ folic acid; $55 \mathrm{mg}$ niacin; $14 \mathrm{mg}$ Ca-pantothenate; $0.1 \mathrm{mg}$ D-biotin.

${ }^{2}$ Provided per kilogram of diet: $50 \mathrm{mg} \mathrm{Mn}\left(\right.$ as $\mathrm{MnO}_{2}$ ); $620 \mathrm{mg} \mathrm{Zn}$ (as $\mathrm{ZnSO}_{4}$ ); $5 \mathrm{mg} \mathrm{Cu}$ (as $\mathrm{CuSO}_{4} \cdot 5 \mathrm{H}_{2} \mathrm{O}$ ); $40 \mathrm{mg} \mathrm{Fe}\left(\right.$ as $\mathrm{FeSO}_{4} \cdot 7 \mathrm{H}_{2} \mathrm{O}$ ); $0.3 \mathrm{mg}$ $\mathrm{Co}\left(\right.$ as $\left.\mathrm{CoSO}_{4} \cdot 5 \mathrm{H}_{2} \mathrm{O}\right) ; 1.5 \mathrm{mg} \mathrm{I}$ (as $\mathrm{KI}$ ); $0.15 \mathrm{mg} \mathrm{Se}\left(\right.$ as $\mathrm{Na}_{2} \mathrm{SeO}_{3} \cdot 5 \mathrm{H}_{2} \mathrm{O}$ ).

${ }^{3}$ Values for ME were calculated from NRC (1994).
$\mathrm{CON}+0.5 \%$ Schizochytrium powder), and iii) $1.0 \%$ MAP (CON+1.0\% Schizochytrium powder). Dried microalgae from Schizochytrium sp. JBF-06 strain was obtained from JINIS Co., Ltd., Wanju, Korea. The fatty acid content of MAP is shown in Table 2.

\section{Egg production, egg quality and blood profiles}

Daily egg production and egg weight were recorded. Forty eight eggs from each treatment (4 eggs/cage) were randomly collected at 40,43 , and $46 \mathrm{wks}$, and used to determine the egg quality. Haugh unit and yolk color were evaluated, using an egg multi tester (Touhoku Rhythm Co. Ltd., Tokyo, Japan). Eggshell breaking strength was evaluated, using an Eggshell force gauge model II (Robotmation Co., Ltd., Tokyo, Japan); and eggshell thickness was measured, using a dial pipe gauge (Ozaki MFG. Co., Ltd., Tokyo, Japan).

Blood samples were randomly collected from 24 layers in each treatment (2 layers/cage) at 46 wks, using a sterilized syringe and $\mathrm{K}_{3}$ EDTA vacuum tubes (Becton Dickinson Vacutainer Systems, Franklin Lakes, NJ, USA). The blood samples were then centrifuged at 3,000 rpm at $4^{\circ} \mathrm{C}$ for $20 \mathrm{~min}$ within one hour of collection, to separate the serum. The concentration of triglyceride and total cholesterol in the serum samples were determined by enzymatic colorimetric methods (Stein et al., 2002), using an automatic biochemical analyzer (RA-1000, Bayer Corp., Tarrytown, NY, USA).

Table 2. Fatty acid composition of microalgae (Schizochytrium) powder

\begin{tabular}{lc}
\hline Fatty acid & \% total fatty acids \\
\hline Lauric acid (C12:0) & 0.20 \\
Myristic acid (C14:0) & 8.95 \\
Pentadecanoic acid (C15:0) & 2.19 \\
Palmitic acid (C16:0) & 38.01 \\
Heptadecanoic acid (C17:0) & 0.85 \\
Stearic acid (C18:0) & 1.47 \\
Linoleic acid (C18:2n-6) & 0.23 \\
$\alpha$-Linolenic acid (C18:3n-3) & 0.59 \\
$\gamma$-Linolenic acid (C18:3n-6) & 0.23 \\
Arachidic acid (C20:0) & 0.52 \\
Heneicosanoic acid (C21:0) & 0.33 \\
Dihomo- $\gamma$-linolenic acid (C20:3n-6) & 0.33 \\
Arachidonic acid (C20:4n-6) & 0.49 \\
Behenic acid (C22:0) & 0.39 \\
Eicosapentaenoic acid (C20:5n-3) & 0.72 \\
Docosapentaenoic acid (C22:5n-6) & 6.74 \\
Docosahexaenoic acid (C22:6n-3) & 37.63 \\
Saturated fatty acid & 52.91 \\
Unsaturated fatty acid & 46.96 \\
n-3/n-6 fatty acid & 5.58 \\
\hline
\end{tabular}


Table 3. Effects of dietary microalgae (Schizochytrium) supplementation on egg production and egg weight in layers

\begin{tabular}{lcccccc}
\hline & CON & \multirow{2}{*}{ MAP 0.5\% } & \multirow{2}{*}{ MAP 1.0\% } & \multirow{2}{*}{ SEM } & \multicolumn{2}{c}{ p-value } \\
\cline { 5 - 7 } & & & & & Linear & Quadratic \\
\hline Egg production (\%) & 80.3 & 79.1 & 81.0 & 0.5 & 0.482 & 0.089 \\
$\quad$ 40 to 43 wks & 84.6 & 87.7 & 90.8 & 1.3 & 0.034 & 1.000 \\
44 to 46 wks & & & & & \\
Egg weight (g) & 61.8 & 61.4 & 60.7 & 1.1 & 0.466 & 0.903 \\
$\quad$ Initial (40 wks) & 61.9 & 60.3 & 59.3 & 1.3 & 0.189 & 0.862 \\
43 wks & 59.7 & 60.4 & 60.5 & 0.9 & 0.504 & 0.884 \\
Final (46 wks) & & & & &
\end{tabular}

MAP, microalgae powder; SEM, standard errors of means.

${ }^{1} \mathrm{CON}=$ basal diet; MAP $0.5 \%=$ basal diet+0.5\% Schizochytrium powder; MAP $1.0 \%=$ basal diet+1.0\% Schizochytrium powder. Means based on 12 cages and 6 hens per cage.

\section{Fatty acid composition of egg yolk}

At the end of the experiment (46 wks), 48 eggs were randomly selected from each treatment (4 eggs/cage), and the fatty acid composition of egg yolk was determined according to the modified method of Kim et al. (2003). Briefly, the lipid from the egg yolk was extracted with hexane/isopropanol $(3: 2 \mathrm{v} / \mathrm{v})$. The extracted lipids were mixed with $0.5 \mathrm{~mL}$ of toluene and $2 \mathrm{~mL}$ of $5 \% \mathrm{KOH}-\mathrm{MeOH}$, and heated at $70^{\circ} \mathrm{C}$ for $8 \mathrm{~min}$; and then $2 \mathrm{~mL}$ of $14 \% \mathrm{BF} 3-$ $\mathrm{MeOH}$ was added to the above mixture, and heated at $70^{\circ} \mathrm{C}$ for $2 \mathrm{~min}$. The fatty acid methyl esters (FAME) were extracted with $3 \mathrm{~mL}$ of $5 \% \mathrm{NaCl}$ and $1 \mathrm{~mL}$ of hexane. Samples were analyzed for total fatty acids, using an HP 5,890 gas chromatography with a flame ionization detector (Hewlett Packard 5890 Series II, Palo Alto, CA, USA). The FAME were separated using a Supelcowax-10 fused silica capillary column $(100 \mathrm{~m} \times 0.32 \mathrm{~mm} \times 0.25 \mu \mathrm{m}$; Supelco, Inc., Bellefonte, PA, USA), with $1.2 \mathrm{~mL} / \mathrm{min}$ of helium flow. The oven temperature was increased from $220^{\circ} \mathrm{C}$ to $240^{\circ} \mathrm{C}$, at the rate of $2^{\circ} \mathrm{C} / \mathrm{min}$. Temperatures of the injector and detector were $240^{\circ} \mathrm{C}$ and $250^{\circ} \mathrm{C}$, respectively. The peak of fatty acids were identified by comparing the retention time and peak area of each fatty acid standard, respectively. The content of each fatty acid was expressed as a percentage of the sum of all of the fatty acids analyzed.

\section{Statistical analysis}

Data were statistically analyzed by analysis of variance, using general linear model procedure of the SAS program (SAS, 2002), for a completely randomized design. Mean values and standard errors of means are reported. Orthogonal polynomial contrast was conducted to measure the linear and quadratic effects for increasing the MAP levels on all measurements. Statements of statistical significance were based on $\mathrm{p}<0.05$.

\section{RESULTS}

\section{Egg production}

Layers fed with diets supplemented with MAP during 40 to 43 wks showed no significant difference in egg production, compared with the control treatment. However, layers fed with MAP showed significantly higher egg production during 44 to $46 \mathrm{wks}$, as dietary MAP increased from $0.5 \%$ to $1.0 \%$ (linear, $\mathrm{p}=0.034$ ); but there was no significant difference in egg weight (Table 3 ).

\section{Blood profiles}

Blood triglyceride concentrations increased quadratically in MAP treatment, compared to control treatment $(\mathrm{p}=0.034)$. Similarly, total cholesterol concentrations of blood also increased quadratically $(\mathrm{p}=$ 0.039, Table 4).

\section{Egg quality}

There were no significant differences in Haugh unit and egg breaking strength of layers fed with different levels of MAP in diets. However, the yolk color index was found to quadratically increase, compared with the control group, at 46th wk $(p=0.044)$. Also, there was a linear effect on

Table 4. Effects of dietary microalgae (Schizochytrium) supplementation on blood lipid metabolites in layers

\begin{tabular}{lccccccc}
\hline & \multirow{2}{*}{ CON $^{1}$} & MAP 0.5\% & \multirow{2}{*}{ MAP 1.0\% } & \multirow{2}{*}{ SEM } & & \multicolumn{2}{c}{ p-value } \\
\cline { 5 - 7 } & & & & & Linear & Quadratic \\
\hline 46 wks & 1,936 & 1,856 & 1,881 & 164 & 0.073 & 0.034 \\
Triglyceride (mg/dL) & 133.8 & 115.7 & 118.5 & 14 & 0.092 & 0.039 \\
Total cholesterol (mg/dL) & &
\end{tabular}

MAP, microalgae powder; SEM, standard errors of means.

${ }^{1} \mathrm{CON}=$ basal diet; MAP $0.5 \%=$ basal diet $+0.5 \%$ Schizochytrium powder; MAP $1.0 \%=$ basal diet+1.0\% Schizochytrium powder. Means based on 12 cages and 2 hens per cage. 
Table 5. Effects of dietary microalgae (Schizochytrium) supplementation on egg quality

\begin{tabular}{|c|c|c|c|c|c|c|}
\hline & \multirow{2}{*}{$\mathrm{CON}^{1}$} & \multirow{2}{*}{ MAP $0.5 \%$} & \multirow{2}{*}{ MAP $1.0 \%$} & \multirow{2}{*}{ SEM } & \multicolumn{2}{|c|}{ p-value } \\
\hline & & & & & Linear & Quadratic \\
\hline \multicolumn{7}{|l|}{ Haugh unit } \\
\hline Initial (40 wks) & 90.7 & 89.5 & 91.8 & 0.83 & 0.366 & 0.101 \\
\hline 43 wks & 91.4 & 91.5 & 91.6 & 0.99 & 0.768 & 0.448 \\
\hline Final (46wks) & 91.6 & 92.5 & 93.1 & 0.84 & 0.279 & 0.619 \\
\hline \multicolumn{7}{|l|}{ Yolk color } \\
\hline Initial (40 wks) & 7.9 & 7.6 & 8.1 & 0.22 & 0.427 & 0.159 \\
\hline 43 wks & 8.9 & 8.8 & 8.8 & 0.12 & 0.430 & 0.647 \\
\hline Final (46wks) & 8.7 & 9.0 & 8.8 & 0.10 & 0.370 & 0.044 \\
\hline \multicolumn{7}{|c|}{ Eggshell strength $\left(\mathrm{kg} / \mathrm{cm}^{2}\right)$} \\
\hline Initial (40 wks) & 4.57 & 4.46 & 4.53 & 0.10 & 0.946 & 0.529 \\
\hline 43 wks & 4.30 & 4.30 & 4.42 & 0.10 & 0.739 & 0.733 \\
\hline Final (46wks) & 4.23 & 4.21 & 4.20 & 0.16 & 0.874 & 0.981 \\
\hline \multicolumn{7}{|c|}{ Eggshell thickness $(\mu \mathrm{m})$} \\
\hline Initial (40 wks) & 397 & 404 & 404 & 0.40 & 0.243 & 0.549 \\
\hline 43 wks & 382 & 379 & 384 & 0.56 & 0.855 & 0.606 \\
\hline Final (46wks) & 367 & 379 & 385 & 0.40 & 0.003 & 0.580 \\
\hline
\end{tabular}

MAP, microalgae powder; SEM, standard errors of means.

${ }^{1} \mathrm{CON}=$ basal diet; MAP $0.5 \%=$ basal diet $+0.5 \%$ Schizochytrium powder; MAP $1.0 \%=$ basal diet $+1.0 \%$ Schizochytrium powder. Means based on 12 cages and 4 eggs per cage.

eggshell thickness, as dietary levels of MAP increased at 46th wk $(\mathrm{p}=0.003$, Table 5).

\section{Egg yolk fatty acid}

The fatty acid composition of egg yolk is shown in Table 6. Palmitic acid (C16:0), DHA (C22:6n-3) and saturated fatty acid (SFA) compositions increased linearly, in layers fed with MAP $(\mathrm{p}=0.044, \mathrm{p}=0.010$, and $\mathrm{p}=0.011$, respectively). The eicosapentaenoic acid (EPA; C20:5n-3) composition was also found to be higher in $0.5 \%$ MAP treatment, than in $\mathrm{CON}$ and $1.0 \%$ MAP treatments; and it had quadratic $(p=0.008)$ effect. Linoleic acid $(C 18: 2 n-6)$, n-6 fatty acid, unsaturated fatty acid (USFA) composition and USFA/SFA ratio decreased in layers fed with MPA (linear, $p=0.013, p=0.013, p=0.002$, and $p=0.005$ ). In addition, n-6/n-3 fatty acid ratio also decreased as dietary levels of MAP increased, and it had a linear $(\mathrm{p}=0.023)$ effect.

\section{DISCUSSION}

Some species of the genus Thraustochytrium, such as

Table 6. Effects of dietary microalgae (Schizochytrium) supplementation on fatty acid composition of egg yolk

\begin{tabular}{|c|c|c|c|c|c|c|}
\hline & \multirow{2}{*}{$\mathrm{CON}^{1}$} & \multirow{2}{*}{ MAP $0.5 \%$} & \multirow{2}{*}{ MAP $1.0 \%$} & \multirow{2}{*}{ SEM } & \multicolumn{2}{|c|}{$\mathrm{p}$-value } \\
\hline & & & & & Linear & Quadratic \\
\hline Myristic acid (C14:0) (\%) & 0.41 & 0.44 & 0.44 & 0.03 & 0.420 & 0.771 \\
\hline Palmitic acid (C16:0) (\%) & 27.06 & 26.56 & 29.02 & 0.48 & 0.044 & 0.065 \\
\hline Palmitoleic acid (C16:1) (\%) & 2.82 & 2.97 & 2.84 & 0.23 & 0.969 & 0.650 \\
\hline Stearic acid $(\mathrm{C} 18: 0)(\%)$ & 8.77 & 9.44 & 9.45 & 0.29 & 0.145 & 0.363 \\
\hline Oleic acid $(\mathrm{C} 18: 1 \mathrm{n}-9)(\%)$ & 44.26 & 45.03 & 43.98 & 0.56 & 0.747 & 0.261 \\
\hline Linoleic acid (C18:2n-6) (\%) & 12.02 & 10.97 & 8.83 & 0.53 & 0.013 & 0.446 \\
\hline Eicosapentaenoic acid (C20:5n-3) (\%) & 0.09 & 0.11 & 0.09 & 0.01 & 1.000 & 0.008 \\
\hline Docosahexaenoic acid (C22:6n-3) (\%) & 0.70 & 0.75 & 0.88 & 0.03 & 0.010 & 0.297 \\
\hline n-6 fatty acid $(\%)$ & 12.16 & 11.15 & 8.95 & 0.53 & 0.013 & 0.416 \\
\hline n-3 fatty acid $(\%)$ & 1.07 & 1.36 & 1.47 & 0.14 & 0.119 & 0.622 \\
\hline$n-6 / n-3$ fatty acid ratio & 11.36 & 8.20 & 6.08 & 1.12 & 0.023 & 0.548 \\
\hline Saturated fatty acid (SFA, \%) & 36.26 & 36.53 & 38.97 & 0.43 & 0.011 & 0.107 \\
\hline Unsaturated fatty acid (USFA, \%) & 58.40 & 57.98 & 55.73 & 0.26 & 0.002 & 0.047 \\
\hline USFA/SFA & 1.61 & 1.59 & 1.43 & 0.02 & 0.005 & 0.063 \\
\hline
\end{tabular}

MAP, microalgae powder; SEM, standard errors of means.

${ }^{1} \mathrm{CON}=$ basal diet; MAP $0.5 \%=$ basal diet+0.5\% Schizochytrium powder; MAP $1.0 \%=$ basal diet $+1.0 \%$ Schizochytrium powder. Means based on 12 cages and 4 eggs per cage. 
Schizochytrium, are known to contain large amounts of DHA in their cytoplasm, and have been used as alternative sources for commercial DHA production. In the present study, we confirmed that Schizochytrium contains a high DHA concentration of about $37.6 \%$ of total fatty acids (Table 2). We hypothesized that the supplementation of MAP containing high DHA level to layer diets would result in positive effects on blood lipid metabolites and egg yolk fatty acid composition.

The addition of $0.5 \%$ and $1.0 \%$ MAP resulted in dosedependent changes of egg production (44 to $46 \mathrm{wks}$ ); but did not significantly affect egg weight. It is well documented that dietary sources of $n-3$ polyunsaturated fatty acids, such as fish oil, linseed oil and canola oil, have no effect on egg production in layers (Hargis et al., 1991; Mazalli et al., 2004). The results of research on layer's performance responses to dietary microalgae supplementation is inconsistent. Zheng et al. (2012) reported that inclusion of microalgae (Chlorell vulgaris) in the laying hen feed had positive effects on egg production. However, Lemahieu et al. (2013) found that egg production was not significantly affected by supplementation of omega-3 rich microalgae (Phaeodactylum tricornutum, Nannochloropsis oculata, Isochrysis galbana, or Chlorella fusca) to the layers. Since there is currently a lack of useful information regarding the use of microalgae Schizochytrium in layers, our study may not be able to completely explain its improvement of egg production. However, microalgae are generally known to contain many essential amino acids, carotenoids, vitamins, minerals, and USFA; and have received much attention as a potential natural antioxidant. In addition, feeding microalgae (Chlorella vulgaris) to layers also results in increased beneficial microbial diversity in the crop and ceca (Janczyk et al., 2009). Therefore, these nutritional factors and change in the intestinal microbial community seem to be involved in some of the metabolism related to egg production. The findings of our current study imply that MAP from Schizochytrium in the diet may have an improving effect on layer performance; though no significant differences were seen in egg weights between the MAP groups and control.

In the present study, reduced serum levels of triglycerides and cholesterol were observed in layers fed with MAP in the diet. The underlying mechanism in relation to lipid metabolism was unclear, and the active ingredients responsible for the activity have not been identified. However, DHA from fish oil and microalgal sources has been found to have beneficial effect on risk factors for cardiovascular disease, including reductions in blood triglyceride levels and in the triglyceride: HDL-cholesterol ratio, as well as shifts towards moderate elevations in HDLcholesterol levels (Holub, 2009). In a recent study, Chen et al. (2011) suggested the possibility that DHA from a microalgal source can inhibit 3-hydroxy-3-methylglutarylcoenzyme A (HMG-CoA) reductase activity, which reduces cholesterol synthesis, and therefore lowers the plasma cholesterol level. The HMG-CoA reductase is a ratelimiting enzyme in cholesterol biosynthesis; and its inhibition can lead to reduction in plasma cholesterol. In addition, numerous studies indicate that dietary fish oil lowers the level of total cholesterol, low-density lipoprotein and triglycerides. Also, the other probable cause is that decreased levels of blood triglyceride and cholesterol found in MAP groups may be associated with polysaccharides in microalgae. Marine algae contains large quantities of soluble and insoluble dietary fibers (Lahaye and Jegou, 1993), which have been reported as successfully reducing blood lipids (Ara et al., 2002; Werman et al., 2003). Therefore, decreased blood triglyceride and total cholesterol concentration in this study were due to the inclusion of dietary MAP, related to the DHA or polysaccharides content in MAP.

Herber and Van Elswyk (1998) indicated that eggs from hens fed with n-3 fatty acid enriched marine microalgae had significantly increased yolk redness values, as compared with controls. Enhancement of yolk redness values most likely reflects the deposition of marine microalgae carotenoids. Some microalgae ingredients used for egg enrichment with polyunsaturated n-3 fatty acids are natural sources of carotenoids, and their use in layer diets increases the yolk color index. Actually, Schizochytrium algae used in this study had a yellow-dark orange color, although we did not measure the pigments in MAP. Aki et al. (2003) reported high levels of $\beta$-carotene and xanthophylls, including canthaxanthin and astaxanthin, in Schizochytrium; and Kotrbacek et al. (2013) confirmed that carotenoids are efficiently deposited in egg yolk, when added to poultry diets. Therefore, addition of MAP into layer diet efficiently increased yolk color, which gives an opportunity for egg yolk pigmentation. Our study also showed that supplementation of MAP had a beneficial effect on the eggshell thickness. However, until now there was no scientific evidence to support the fact that microalgae can affect the eggshell thickness. In general, marine algae are rich natural sources of trace minerals. We presume that our findings were related to organic minerals contained in MAP influencing the eggshell thickness. The use of microalgae in mineral metabolism in layer needs further investigation

In the present study, n-3 fatty acid concentrations in eggs were found to be significantly increased by MAP supplementation. Considering that MAP contains high DHA, and dietary fat is directly reflected in the fatty acid profiles of egg, the rise in n-3 fatty acid levels is easily understood. Oleaginous marine microorganism such as Schizochytrium 
has recently become available as a source of fish oils, for various functional food fortifications. Therefore, some of the strains, including Schizochytrium, have been mainly used as poultry feed additives to produce omega 3 -enriched eggs (Chin et al., 2006; Lemahieu et al., 2013). Similar to previous reports, MAP leads to increased total DHA in the eggs. Polyunsaturated fatty acids intake including n-3 and n-6 fatty acids, has beneficial effects on both animal and consumer health. However, some limited studies imply that excessive intake of n-6 relative to n-3 fatty acids was associated with an increased in cardiovascular heart disease or inflammatory diseases (Simopoulos, 2003; Hibbeln et al., 2006). Since consuming a higher amount of $n-6$ fatty acids has been closely associated with negative health impact, attempts have been made to manipulate the fatty acid profile in human diet, using several fat sources (Huang et al., 1990; Shin et al., 2011). Dietary n-6 fatty acid ratio, relative to n-3 fatty acid, was recommended to be decreased, for ideal nutritive value in humans (Gerster, 1998); but it was lower in our study, in both the 0.5\% MAP and 1.0\% MAP groups ( 8.20 and 6.08 , respectively). On the other hand, control group showeda higher value (11.36) than these groups. It can thus be proposed that MAP fed to layers is a feeding practice that is able to decrease the $n-6$ to $n-3$ fatty acid ratio in their eggs. Total SFA significantly increased in a linear manner in egg yolks of layers fed with MAP diets. An increase in proportion of SFA seems mainly to be associated with higher n-6 fatty acids and lower C16:0.

In conclusion, supplementation of MAP in the diet of layers had a beneficial effect on egg production, egg weight, yolk color and blood lipid profiles of layers, in comparison with the control group. In addition, MAP could enhance the DHA and EPA concentrations in eggs, and decrease n-6 fatty acid or n-6/n-3 fatty acid ratio.

\section{ACKNOWLEDGMENTS}

The present research was conducted by the research fund of Dankook University in 2014.

\section{REFERENCES}

Aki, T., K. Hachida, M. Yoshinaga, Y. Katai, T. Yamasaki, S. Kawamoto, T. Kakizono, T. Yamaoka, S. Shigeta, O. Suzuki, and K. Ono. 2003. Thraustochytrid as a potential source of carotenoids. J. Am. Oil. Chem. Soc. 80:789-794.

Ara, J., V. Sultana, R. Qasim, and V. U. Ahmad. 2002. Hypolipidaemic activity of seaweed from Karachi coast. Phytother. Res.16:479-483.

Becker, W. 2004. Microalgae in human and animal nutrition. In Handbook of Microalgal Culture: Biotechnology and Applied Phycology (Ed. A. Richmond). Blackwell, Oxford, UK. pp. 312-351.
Chen, J., Y. Jiang, K. Y. Ma, F. Chen, and Z. Y. Chen. 2011. Microalga decreases plasma cholesterol by down-regulation of intestinal NPC1L1, hepatic LDL receptor, and HMG-CoA reductase. J. Agric. Food Chem. 59:6790-6797.

Chin, H. J., T. F. Shen, H. P. Su, and S. T. Ding. 2006. Schizochytrium limacinum SR-21 as a source of docosahexaenoic acid: optimal growth and use as a dietary supplement for laying hens. Aust. J. Agric. Res. 57:13-20.

Dvir, I., A. H. Stark, R. Chayoth, Z. Madar, and S. M. Arad. 2009. Hypocholesterolemic effects of nutraceuticals produced from the red microalga Porphyridium sp. in rats. Nutrients 1:156167.

Gatrell, S., K. Lum, J. Kim, and X. G. Lei. 2014. Nonruminant Nutrition Symposium: Potential of defatted microalgae from the biofuel industry as an ingredient to replace corn and soybean meal in swine and poultry diets. J. Anim. Sci. 92:1306-1314.

Gerster, H. 1998. Can adults adequately convert alpha-linolenic acid (18:3n-3) to eicosapentaenoic acid (20:5n-3) and docosahexaenoic acid (22:6n-3)? Int. J. Vitam. Nutr. Res. 68:159-173.

Hargis, P. S., M. E. Van Elswyk, and B. M. Hargis. 1991. Dietary modification of yolk lipid with menhaden oil. Poult. Sci. 70:874-883.

Hata, Y., K. Nakajima, J. Uchida, H. Hidaka, and T. Nakano. 2002. Clinical effects of brown seaweed Undaria pinnatifida (wakame) on blood pressure in hypertensive subjects. J. Clin. Biochem. Nutr. 30:43-53.

Herber, S. M. and M. E. Van Elswyk. 1996. Dietary marine algae promotes efficient deposition of n-3 fatty acids for the production of enriched shell eggs. Poult. Sci. 75:1501-1507.

Herber, S. M. and M. E. Van Elswyk. 1998. Dietary marine algae maintains egg consumer acceptability while enhancing yolk color. Poult. Sci. 77:493-496.

Hibbeln, J. R., L. R. G. Nieminen, T. L. Blasbalg, J. A. Riggs, and W. E. M. Lands. 2006. Healthy intakes of n-3 and n-6 fatty acids: Estimations considering worldwide diversity. Am. J. Clin. Nutr. 83:1483S-1493S.

Hirahashi, T., M. Matsumoto, K. Hazeki, Y. Saeki, M. Ui, and T. Seya. 2002. Activation of the human innate immune system by Spirulina: augmentation of interferon production and NK cytotoxicity by oral administration of hot water extract of Spirulina platensis. Int. Immunopharmacol. 2:423-434.

Holub, B. J. 2009. Docosahexaenoic acid (DHA) and cardiovascular disease risk factors. Prostaglandins Leukot. Essent. Fatty Acids 81:199-204.

Huang, Z. B., R. G. Ackman, W. M. N. Ratnayake, and F. G. Proudfoot. 1990. Effect of dietary fish oil on n-3 fatty acid levels in chicken eggs and thigh flesh. J. Agric. Food Chem. 38:743-747.

Janczyk, P., B. Halle, and B. Souffrant. 2009. Microbial community composition of the crop and ceca contents of laying hens fed diets supplemented with Chlorella vulgaris. Poult. Sci. 88:2324-2332.

Jimenez-Escrig, A., I. Jimenez-Jimenez, R. Pulido, and F. SauraCalixto. 2001. Antioxidant activity of fresh and processed edible seaweeds. J. Sci. Food Agric. 81:530-534.

Kim, Y. J., K. W. Lee, S. Lee, H. Kim, and H. J. Lee. 2003. The 
production of high-purity conjugated linoleic acid (CLA) using two-step urea-inclusion crystallization and hydrophilic arginine-CLA complex. J. Food Sci. 68:1948-1951.

Kotrbacek, V., M. Skrivan, J. Kopecky, O. Penkava, P. Hudeckova, I. Uhríkova, and J. Doubek. 2013. Retention of carotenoids in egg yolks of laying hens supplemented with heterotrophic Chlorella. Czech J. Anim. Sci. 58:193-200.

Lahaye, M. and D. Jegou. 1993. Chemical and physical-chemical characteristics of dietary fibers from Ulva lactuca (L.) Thuret and Enteromorpha compressa (L.) Grev. J. Appl. Physiol. 5:195-200.

Lemahieu, C., C. Bruneel, R. Termote-Verhalle, K. Muylaert, J. Buyse, and I. Foubert. 2013. Impact of feed supplementation with different omega-3 rich microalgae species on enrichment of eggs of laying hens. Food Chem. 14:4051-4059.

Lum, K. K., J. Kim, and X. G. Lei. 2013. Dual potential of microalgae as a sustainable biofuel feedstock and animal feed. J. Anim. Sci. Biotechnol. 4:53.

Mazalli, M. R., D. E. Faria, D. Salvador, and D. T. Ito. 2004. A Comparison of the feeding value of different sources of fats for laying hens: 1. Performance characteristics. J. Appl. Poult. Res. 13:274-279.

NRC. 1994. Nutrient Requirements of Poultry. 9th ed, National Academy Press. Washington, DC, USA.

Sardi, L., G. Martelli, L. Lambertini, P. Parisini, and A. Mordenti. 2006. Effects of a dietary supplement of DHA-rich marine algae on Italian heavy pig production parameters. Livest. Sci. 103:95-103.

SAS. 2002. SAS User's Guide: Statistics, Version 9.0. SAS Inst. Inc., Cary, NC, USA.
Shin, D., G. Kakani, A. Karimi, Y. M. Cho, S. W. Kim, Y. G. Ko, K. S. Shim, and J. H. Park. 2011. Influence of dietary conjugated linoleic acid and its combination with flaxseed oil or fish oil on saturated fatty acid and n-3 to n- 6 fatty acid ratio in broiler chicken meat. Asian Australas. J. Anim. Sci. 24:1249-1255.

Simopoulos, A. P. 2003. Importance of the ratio of omega6/omega-3 essential fatty acids: Evolutionary aspects. World Rev. Nutr. Diet. 92:171-174.

Spolaore, P., C. Joannis-Cassan, E. Duran, and A. Isambert. 2006. Commercial applications of microalgae. J. Biosci. Bioeng. 101:87-96.

Stamey, J. A., D. M. Shepherd, M. J. de Veth, and B. A. Corl. 2012. Use of algae or algal oil rich in n-3 fatty acids as a feed supplement for dairy cattle. J. Dairy Sci. 95:5269-5275.

Stein, J. H., C. M. Carlsson, K. Papcke-Benson, J. A. Einerson, P. E. McBride, and D. A. Wiebe. 2002. Inaccuracy of lipid measurements with the portable Cholestech L.D.X analyzer in patients with hypercholesterolemia. Clin. Chem. 48:284-290.

Trentacoste, E. M., R. P. Shrestha, S. R. Smith, C. Gle, A. C. Hartmann, M. Hildebrand, and W. H. Gerwick. 2013. Metabolic engineering of lipid catabolism increases microalgal lipid accumulation without compromising growth. Proc. Natl. Acad. Sci. 110:19748-19753.

Werman, M. J., A. Sukenik, and S. Mokady. 2003. Effects of the marine unicellular alga Nannochloropsis sp. to reduce the plasma and liver cholesterol levels in male rats fed on diets with cholesterol. Biosci. Biotechnol. Biochem. 67:2266-2268.

Zheng, L., S. T. Oh, J. Y. Jeon, B. H. Moon, H. S. Kwon, S. U. Lim, B. K. An, and C. W. Kang. 2012. The dietary effects of fermented Chlorella vulgaris $\left(\mathrm{CBT}^{\circledR}\right)$ on production performance, liver lipids and intestinal microflora in laying hens. Asian Australas. J. Anim. Sci. 25:261-266. 